\title{
Hand Digit 2 Proximal Phalanx
}

National Cancer Institute

\section{Source}

National Cancer Institute. Hand Digit 2 Proximal Phalanx. NCI Thesaurus. Code C142304.

A long bone in the second finger, as counted from the thenar side of the hand; it is located between, and articulates with, the second metacarpal and the middle phalanx. 